\title{
ANALISIS NILAI TAMBAH DAN RENTABILITAS AGROINDUSTRI TAHU BULAT
}

(Studi Kasus Pada Perusahaan Tahu Bulat Asian di Desa Muktisari

Kecamatan Cipaku Kabupaten Ciamis)

\author{
Oleh : \\ Iif Latifah ${ }^{1}$, Yus Rusman ${ }^{2}$, Tito Hardiyanto ${ }^{3}$ \\ ${ }^{13}$ Fakultas Pertanian Universitas Galuh \\ ${ }^{2}$ Fakultas Pertanian Universitas Padjadjaran
}

\begin{abstract}
Abstrak
Penelitian ini bertujuan untuk mengetahui besarnya :1) Biaya, penerimaan, pendapatan dan $\mathrm{R} / \mathrm{C}$ agroindustri tahu bulat dalam satu kali proses produksi. 2) Nilai tambah agroindustri tahu bulat dalam satu kali proses produksi, dan 3) Nilai rentabilitas agroindustri tahu bulat dalam satu kali proses produksi. Metode yang digunakan dalam penelitian ini adalah studi kasus pada seorang perajin tahu bulat di Desa Muktisari Kecamatan Cipaku Kabupaten Ciamis. Responden yang diambil dalam penelitian ini diambil secara sengaja (purposive sampling), yaitu pada agroindustri tahu bulat perusahaan Asian Desa Muktisari Kecamatan Cipaku Kabupaten Ciamis. Hasil penelitian menunjukkan bahwa : 1) Besarnya biaya produksi agroindustri tahu bulat pada perusahaan Asian dalam satu kali proses produksi adalah Rp.44.872.306,71, penerimaan sebesar Rp.85.705.000,00 pendapatan sebesar Rp. 40.832.693,29, dan R/C sebesar 1,90. 2) Besarnya nilai tambah pada agroindustri tahu bulat pada perusahaan Asian dalam satu kali proses produksi sebesar Rp.11.964,46 per kilogram. 3) Besarnya nilai rentabilitas pada agroindustri tahu bulat pada perusahaan Asian dalam satu kali proses produksi sebesar 90,99 persen.
\end{abstract}

\section{Kata Kunci : Biaya, Pendapatan, R/C, Nilai Tambah, Rentabilitas.}

\section{PENDAHULUAN}

Indonesia merupakan negara agraris dimana sektor pertanian memiliki peran penting dalam pertumbuhan ekonomi nasional. Hal ini dapat dilihat dari banyaknya penduduk atau tenaga kerja yang hidup atau bekerja di sektor pertanian dan produk nasional berasal dari pertanian. Program pembangunan pertanian diarahkan untuk dapat memberikan pelayanan yang prima kepada petani, sehingga dapat menumbuhkan kesadaran bagi masyarakat untuk berpartisipasi aktif dalam pembangunan pertanian (Rahim dan Hastuti, 2007).

Kegiatan agroindustri merupakan bagian integral dari pembangunan sektor pertanian. Efek agroindustri mampu mentransformasikan produk primer ke produk olahan sekaligus budaya kerja bernilai tambah rendah menjadi budaya kerja industrial modern yang menciptakan nilai tambah tinggi (Suryana, 2005).

Di Indonesia kedelai merupakan komoditi tanaman pangan yang amat penting dan strategis dalam ekonomi nasional, karena memiliki peran pokok sebagai pemenuh kebutuhan pangan, pakan dan industri dalam negeri yang setiap tahunnya cenderung meningkat. Kedelai merupakan komoditas pertanian yang mempunyai kandungan unsur gizi yang tinggi sehingga layak untuk dikonsumsi manusia. Permintaan yang meningkat tersebut terutama didorong oleh meningkatnya industri tahu, tempe, kecap dan pakan. Kekurangan bahan mentah kedelai akan terus meningkat dimasa yang akan datang (Adisarwanto, 2008).

Salah satu diversifikasi pangan yang berpotensi untuk dikembangkan yaitu pengolahan kacang kedelai menjadi tahu. Seiring perkembangan zaman kini agroindustri tahu terus berinovasi, salah satunya adalah tahu bulat. Pengembangan agroindustri tahu bulat diharapkan dapat meningkatkan nilai tambah sehingga dapat meningkatkan pula pendapatan pelaku usahanya.

Adapun tujuan dari penelitian ini untuk mengetahui besarnya biaya, penerimaan, pendapatan, dan nilai $\mathrm{R} / \mathrm{C}$ agroindustri tahu bulat pada perusahaan Asian pada satu kali proses produksi, besarnya nilai tambah pada agroindustri tahu bulat pada perusahaan Asian pada satu kali proses produksi, dan besarnya nilai rentabilitas pada agroindustri tahu bulat pada perusahaan Asian pada satu kali proses produksi.

\section{METODE PENELITIAN Jenis Penelitian}


Metode penelitian yang digunakan dalam penelitian ini adalah metode studi kasus, dengan mengambil kasus pada Agroindustri Tahu Bulat Asian di Desa Muktisari Kecamatan Cipaku Kabupaten Ciamis. Menurut Nazir (2009) studi kasus adalah penelitian tentang satu objek penelitian yang berkenaan dengan suatu fase spesifik atau khas dari keseluruhan personalitas

\section{Teknik Pengumpulan Data}

Teknik pengumpulan data yang digunakan dalam penelitian ini meliputi data primer dan data sekunder. Data primer diperoleh dari wawancara langsung dengan pengusaha agroindustri Tahu bulat Asian dengan menggunakan daftar pertanyaan dalam kuesioner yang telah disediakan. Data sekunder bersumber dari instansi terkait, jurnal buku pendukung penelitian dan literatur yang lainnya.

Penarikan sampel tempat penelitian dilakukan secara sengaja (purposive sampling) yaitu pada seorang pengusaha agroindustri tahu bulat Asian yang merupakan terbesar di Desa Muktisari Kecamatan Cipaku Kabupaten Ciamis. Menurut Arikunto (2006) teknik penarikan sampel ini didasarkan atas adanya tujuan tertentu, keuntungannya terletak pada ketepatan peneliti memilih sumber data sesuai dengan variabel yang diteliti.

\section{Rancangan Analisis Data}

1. Biaya Total Agroindustri tahu bulat dihitung menggunakan rumus menurut Suratiyah (2015) sebagai berikut:

$\mathrm{TC}=\mathrm{FC}+\mathrm{VC}$

Dimana :

TC $=$ Total Cost (Biaya Total)

$\mathrm{FC}=$ Fixed Cost (Biaya Tetap)

$\mathrm{VC}=$ Variable Cost (Biaya Variabel)
2. Penerimaan dihitung menggunakan rumus menurut Suratiyah (2015) sebagai berikut:

$$
\begin{aligned}
& \mathrm{P}=\mathrm{Y} \cdot \mathrm{Py} \\
& \text { Dimana }: \\
& \mathrm{P}=\text { Penerimaan } \\
& \mathrm{Y}=\text { Jumlah produksi } \\
& \mathrm{Py}=\text { Harga produksi }
\end{aligned}
$$

3. Pendapatan dihitung menggunakan rumus menurut Suratiyah (2015) sebagai berikut: $\mathrm{I}=\mathrm{P}-\mathrm{TC}$

Keterangan:

I = Pendapatan

$\mathrm{P}=$ Penerimaan

$\mathrm{TC}=$ Total Cost (Biaya Total)

4. $\mathrm{R} / \mathrm{C}$ dihitung menggunakan rumus menurut Rodjak (2006) sebagai berikut:

$\mathrm{R} / \mathrm{C}=\mathrm{TR} / \mathrm{TC}$

Keterangan :

$\mathrm{R} / \mathrm{C}=$ Revenue Cost Rasio

$\mathrm{TR}=$ Penerimaan Total (Total Revenue)

TC = Biaya Total (Total Cost)

Dengan kriteria sebagai berikut:

- $\mathrm{R} / \mathrm{C}>1$, maka setiap Rp.1 yang dikeluarkan menghasilkan penerimaan lebih dari satu rupiah, berarti agroindustri menguntungkan dan layak untuk diteruskan.

- $\mathrm{R} / \mathrm{C}=1$, maka setiap Rp.1 yang dikeluarkan menghasilkan penerimaan sama dengan satu rupiah, berarti agroindustri berada pada titik impas (balik modal) karena tidak untung, tidak rugi.

- $\mathrm{RC}<1$, maka setiap Rp.1 yang dikeluarkan menghasilkan penerimaan lebih kecil dari 1, berarti agroindustri mengalami kerugian dan tidak layak untuk diteruskan.

5. Analisis Nilai Tambah dihitung menggunakan rumus menurut Hayami dalam Suprapto (2007) sebagai berikut:

\begin{tabular}{|c|l|l|}
\hline No. & \multicolumn{1}{|c|}{ Variabel } & \multirow{2}{*}{ Nlai Simbol } \\
\hline I. & Output, Input dan Harga & $(1)$ \\
\hline 1. & Output (kg) & $(2)$ \\
\hline 2. & Input (kg) & $(3)$ \\
\hline 3. & Tenaga Kerja (HOK) & $(4)=(1) /(2)$ \\
\hline 4. & Faktor konversi & $(5)=(3) /(2)$ \\
\hline 5. & Koefisien Tenaga Kerja (HOK) & $(6)$ \\
\hline 6. & Harga Output (Rp/kg) & $(7)$ \\
\hline 7. & Upah Rata-Rata Tenaga Kerja (Rp/HOK) & \\
\hline II. & Penerimaan dan Keuntungan & \\
\hline
\end{tabular}




\begin{tabular}{|l|l|l|}
\hline 8. & Harga Bahan Baku (Rp/kg) & $(8)$ \\
\hline 9. & Sumbangan Input Lain (Rp/kg) & $(9)$ \\
\hline 10. & Nilai output (Rp/kg) & $(10)=(4) \times(6)$ \\
\hline 11. & a. Nilai Tambah (Rp/kg) & $(11 \mathrm{a})=(10)-(9)-(8)$ \\
\hline & b. Rasio Nilai Tambah $(\%)$ & $(11 \mathrm{~b})=(11 \mathrm{a}) /(10) \times 100 \%$ \\
\hline 12. & a. Imbalan Tenaga Kerja (Rp/kg) & $(12 \mathrm{a})=(5) \mathrm{x}(7)$ \\
\hline & b. Pangsa Tenaga Kerja (\%) & $(12 \mathrm{~b})=(12 \mathrm{a}) /(11 \mathrm{a}) \times 100 \%$ \\
\hline 13. & a. Keuntungan (Rp/kg) & $(13 \mathrm{a})=(11 \mathrm{a})-(12 \mathrm{a})$ \\
\hline & b. Tingkat Keuntungan (\%) & $(13 \mathrm{~b})=(13 \mathrm{a}) /(11 \mathrm{a}) \times 100 \%$ \\
\hline III. & Balas Jasa Pemilik Faktor-Faktor Produksi & \\
\hline 14. & Margin (Rp/kg) & $(14)=(10)-(8)$ \\
\hline & a.Pendapatan Tenaga Kerja Langsung $(\%)$ & $(14 \mathrm{a})=(12 \mathrm{a}) /(14) \times 100 \%$ \\
\hline & b. Sumbangan Input Lain $(\%)$ & $(14 \mathrm{~b})=(9) /(14) \times 100 \%$ \\
\hline & c.Keuntungan Pemilik Perusahaan $(\%)$ & $(14 \mathrm{c})=(13 \mathrm{a}) /(14) \times 100 \%$ \\
\hline
\end{tabular}

Sumber : Hayami dalam Suprapto, 2007.

6. Rentabilitas dihitung dengan menggunakan rumus Riyanto (2010) yaitu:

$\mathrm{R}=\frac{L}{M} \times 100 \%$

\section{Tempat dan Waktu Penelitian}

Penelitian ini dilaksanakan pada agroindustri tahu bulat Asian di Desa Muktisari Kecamatan Cipaku Kabupaten Ciamis. Adapun waktu penelitian ini dibagi dalam beberapa tahapan sebagai berikut:

1. Tahapan survei pendahuluan, penulisan usulan penelitian, dan Seminar Usulan Penelitian dilaksanakan pada bulan Maret sampai dengan April 2016.

2. Tahapan pengumpulan dan pengolahan data dilaksanakan pada bulan April 2016.

3. Tahapan penulisan laporan penelitian dilaksanakan pada bulan Mei 2016 sampai dengan selesai.

\section{HASIL DAN PEMBAHASAN}

\section{A. Identitas Responden}

Responden dalam penelitian ini adalah Bapak Aan Targana yang merupakan pengusaha agroindustri tahu bulat Asian, yang beralamat di dusun Cijoho Desa Muktisari Kecamatan Cipaku Kabupaten Ciamis. Identitas responden meliputi beberapa aspek antara lain umur, tingkat pendidikan, jumlah tanggungan keluarga, pengalaman berusaha.

\section{Umur Responden}

Umur responden yang menjalankan agroindustri tahu bulat pada perusahaan Asian adalah 47 tahun, umur tersebut masih termasuk ke dalam umur produktif.

\section{Tingkat Pendidikan}

Pendidikan mempunyai peranan penting dalam mengadopsi teknologi dan keterampilan manajemen untuk meningkatkan usahanya. Tngkat pendidikan yang dicapai oleh responden adalah tamatan Sekolah Dasar (SD).

\section{Pengalaman Usaha Responden}

Pengalaman responden dalam mengusahakan agrondustri tahu bulat yaitu sekitar 8 tahun. Melihat pengalaman tersebut dapat dikatakan bahwa responden sudah lama dalam menjalankan usahanya. Pengalaman berusaha yang cukup lama sangat bermanfaat bagi responden untuk menambah pengetahuan dan keterampilan dari mulai penyediaan sarana produksi sampai dengan memasarkan produk.

\section{Tanggungan Keluarga Responden}

Tanggungan keluarga yang dimaksud dalam penelitian ini adalah jumlah anggota keluarga baik istri, anak maupun anggota keluarga lainnya yang menjadi tanggung jawab responden untuk memenuhi kebutuhan hidupnya. Jumlah tanggungan keluarga responden adalah sebanyak 3 orang yang terdiri dari satu orang istri, satu orang anak, dan satu orang ibu.

\section{B. Analisis Usaha Agroindustri Tahu Bulat}

Analisis usaha agroindustri tahu bulat terdiri atas analisis biaya, penerimaan, pendapatan, nilai tambah dan rentabilitas usaha yang dihitung selama satu kali proses produksi. Analisis Biaya

Biaya produksi adalah korbanan yang digunakan dalam proses produksi untuk menghasilkan produk yang diukur dengan uang atau rupiah.Untuk perhitungan rincian biaya tetap agroindustri tahu bulat dalam satu kali proses produksi dapat dilihat pada Tabel 2 . 
Tabel 2. Rincian Biaya Tetap Pada Agroindustri Tahu Bulat Dalam Satu Kali Proses Produksi.

\begin{tabular}{|r|l|r|r|}
\hline $\begin{array}{c}\text { N } \\
\text { o }\end{array}$ & Jenis Biaya & $\begin{array}{c}\text { Jumlah } \\
\text { Biaya } \\
(\mathbf{R p})\end{array}$ & $\begin{array}{c}\text { Persentase } \\
(\%)\end{array}$ \\
\hline 1 & $\begin{array}{l}\text { Pajak Bumi dan } \\
\text { Bangunan }\end{array}$ & $1.369,86$ & 2,14 \\
\hline 2 & Penyusutan Alat & $46.159,76$ & 72,19 \\
\hline 3 & Izin Usaha & $1.369,86$ & 2,14 \\
\hline 4 & NPWP & 15.000 & 23,47 \\
\hline 5 & $\begin{array}{l}\text { Bunga Modal } \\
\text { Tetap }\end{array}$ & 38,33 & 0,06 \\
\hline & Jumlah & $63.937,81$ & 100,00 \\
\hline
\end{tabular}

Perhitungan rincian biaya variabel agroindustri tahu bulat dalam satu kali proses produksi dapat dilihat pada Tabel 3.

Tabel 3. Rincian Biaya Variabel Agroindustri Tahu Bulat Dalam Satu Kali Proses Produksi.

\begin{tabular}{|c|c|c|c|}
\hline $\begin{array}{l}\mathbf{N} \\
\mathbf{0} \\
\end{array}$ & Jenis Biaya & $\begin{array}{c}\text { Jumlah } \\
\text { Biaya (Rp) }\end{array}$ & $\begin{array}{c}\text { Persentase } \\
(\%)\end{array}$ \\
\hline 1 & $\begin{array}{l}\text { Sarana } \\
\text { Produksi }\end{array}$ & 33.658 .500 & 75,11 \\
\hline 2 & Tenaga Kerja & 11.123 .000 & 24,83 \\
\hline 3 & $\begin{array}{l}\text { Biaya Bunga } \\
\text { Variabel }\end{array}$ & $26.868,9$ & 0,06 \\
\hline & Jumlah & $44.808 .368,9$ & 100,00 \\
\hline
\end{tabular}

Hasil penelitian menunjukkan bahwa besarnya total biaya produksi yang keluarkan agroindustri tahu bulat dalam satu kali proses produksi sebesar Rp.44.872.306,71 yang merupakan penjumlahan dari biaya tetap sebesar Rp. 63.937,81 dengan biaya variabel sebesar Rp. 44.808.368,9.

\section{Analisis Penerimaan dan Pendapatan Usaha Agroindustri Tahu Bulat}

Untuk memperoleh penerimaan usaha tahu bulat pada perusahaan Asian dihitung dengan cara mengalikan hasil produksi tahu bulat dalam satu kali proses produksi dengan harga jual pada saat penelitian dan ditambah dengan penjualan ampas tahu. Jumlah penerimaan agroindustri tahu bulat bisa dilihat pada Tabel 4
Tabel 4. Jumlah Penerimaan Agroindustri Tahu Bulat Dalam Satu Kali Proses Produksi.

\begin{tabular}{|c|l|c|c|c|}
\hline $\begin{array}{c}\mathbf{N} \\
\mathbf{0}\end{array}$ & \multicolumn{1}{|c|}{ Uraian } & $\begin{array}{c}\text { Harga } \\
\text { (Rp) }\end{array}$ & $\begin{array}{c}\text { Total } \\
\text { Produksi }\end{array}$ & $\begin{array}{c}\text { Jumlah } \\
(\text { Rp) }\end{array}$ \\
\hline 1 & $\begin{array}{l}\text { Tahu bulat } \\
\text { (Rp/butir) }\end{array}$ & 200 & 420.000 & 84.000 .000 \\
\hline 2 & $\begin{array}{l}\text { Ampas tahu } \\
\text { (Rp/karung) }\end{array}$ & 11.000 & 155 & 1.705 .000 \\
\hline & Total & & & 85.705 .000 \\
\hline
\end{tabular}

Untuk mengetahui besarnya pendapatan atau keuntungan agroindustri tahu bulat pada perusahaan Asian diperoleh dari penerimaan dikurangi dengan jumlah total biaya produksi. Analisis penerimaan dan pendapatan agroindustri tahu bulat dapat dilihat pada Tabel 5

Tabel 5. Analisis Penerimaan dan Pendapatan Agroindustri Tahu Bulat Dalam Satu Kali Proses Produksi.

\begin{tabular}{|l|l|c|}
\hline No & \multicolumn{1}{|c|}{ Uraian } & Jumlah (Rp) \\
\hline 1 & Penerimaan & $85.705 .000,00$ \\
\hline 2 & $\begin{array}{l}\text { Total biaya } \\
\text { produksi }\end{array}$ & $44.872 .306,71$ \\
\hline 3 & Pendapatan & $40.832 .693,29$ \\
\hline
\end{tabular}

\section{Analisis R/C}

$\mathrm{R} / \mathrm{C}$ digunakan untuk mengetahui menguntungkan atau tidak usaha agroindustri tahu bulat pada perusahaan Asian. R/C merupakan perbandingan antara penerimaan dengan biaya total. Nilai R/C pada agroindustri tahu bulat adalah 1,90.

\section{Analisis Nilai Tambah}

Nilai tambah merupakan selisih antara nilai produk olahan pertanian dengan biaya. Analisis nilai tambah dihitung untuk mengetahui pertambahan kacang kedelai menjadi tahu bulat. Untuk menghitung nilai tambah tahu bulat tersebut digunakan analisis nilai tambah dengan pendekatan struktur produksi (Hayami dalam Suprapto, 2007) dan dapat dilihat pada Tabel 6. 
Tabel 6. Analisis Nilai Tambah Agrindustri Tahu Bulat Dalam Satu Kali Proses Produksi.

\begin{tabular}{|c|l|c|}
\hline No & \multicolumn{1}{|c|}{ variabel } & Nlai Simbol \\
\hline I & Output, Input dan Harga & 420.000 \\
\hline 1 & Output (butir) & 4.200 \\
\hline 2 & Input (kg) & 140 \\
\hline 3 & Tenaga Kerja (HOK) & 100 \\
\hline 4 & Faktor konversi & 0,033 \\
\hline 5 & Koefisien Tenaga Kerja (HOK) & 200 \\
\hline 6 & Harga Output (Rp/butir) & $11.122,86$ \\
\hline 7 & Upah Rata-Rata Tenaga Kerja (Rp/HOK) & 6.500 \\
\hline II & Penerimaan dan Keuntungan & $1.535,54$ \\
\hline 8 & Harga Bahan Baku (Rp/kg) & 20.000 \\
\hline 9 & Sumbangan Input Lain (Rp/kg) & $11.964,46$ \\
\hline 10 & Nilai output (Rp/kg) & 59,82 \\
\hline 11 & a. Nilai Tambah (Rp/kg) & 367,05 \\
\hline & b. Rasio Nilai Tambah (\%) & 3,06 \\
\hline 12 & a. Imbalan Tenaga Kerja (Rp/kg) & $11.597,41$ \\
\hline & b. Pangsa Tenaga Kerja (\%) & 96,93 \\
\hline 13 & a. Keuntungan (Rp/kg) & 13.500 \\
\hline & b. Tingkat Keuntungan (\%) & 2,71 \\
\hline III & Balas Jasa Pemilik Faktor-Faktor Produksi & 11,37 \\
\hline 14 & Margin (Rp/kg) & 85,90 \\
\hline & a. Pendapatan Tenaga Kerja Langsung (\%) & \\
\hline & b. Sumbangan Input Lain (\%) & \\
\hline & c. Keuntungan Pemilik Perusahaan (\%) & \\
\hline
\end{tabular}

Berdasarkan Tabel 6 diketahui bahwa faktor konversi dari kacang kedelai menjadi tahu bulat adalah 100 butir, ini berarti bahwa dari 1 kilogram bahan baku kacang kedelai menghasilkan tahu bulat sebanyak 100 butir. Untuk mendapatkan 100 butir tahu bulat dibentuk dengan ukuran diameter sekitar 2,8 $\mathrm{cm}$. Koefisien tenaga kerja adalah perbedaan antara input tenaga kerja dengan input bahan baku. Koefisien tenaga kerja ini memiliki nilai 0,033 artinya untuk mengolah 1 kilogram bahan baku kacang kedelai menjadi tahu bulat memerlukan curahan tenaga kerja 0,033 HOK.

Sumbangan input lain adalah biaya yang dikeluarkan selain bahan baku dan biaya tenaga kerja untuk mengolah 1 kilogram bahan baku. Sumbangan input lain diperoleh dari penjumlahan biaya bersama (selain biaya bahan baku dan biaya tenaga kerja) dibagi dengan jumlah bahan baku yang digunakan. Sumbangan input lain ini sebesar Rp.1.535,54 per kilogram bahan baku.
Nilai output sebesar Rp. 20.000 per kilogram, nilai ini merupakan perkalian antara faktor konversi dengan harga produk. Nilai output ini menunjukkan besarnya nilai produk yang dihasilkan dari pengolahan satu kilogram bahan baku.

Nilai tambah diperoleh sebesar Rp.11.964,46 per kilogram kacang kedelai dan memberikan sumbangan rasio nilai tambah yaitu sebesar 59,82 persen. Nilai tambah diperoleh dari selisih antara nilai produk dengan harga bahan baku serta sumbangan input lain. Nilai tambah tersebut merupakan nilai tambah kotor karena masih mengandung pendapatan tenaga kerja dan pangsa tenaga kerja.

\section{Rentabilitas Agroindustri Tahu Bulat}

Rentabilitas digunakan untuk melihat kemampuan kegiatan usaha agroindustri tahu bulat dalam menghasilkan laba dari modal (biaya) yang digunakan pada periode tertentu. Berdasarkan hasil perhitungan diketahui, bahwa keuntungan yang diperoleh dari hasil 
usaha agroindustri tahu bulat sebesar Rp.40.832.693,29 dan biaya yang dikeluarkan sebesar Rp.44.872.306,71 maka dengan demikian dapat dihitung nilai rentabilitasnya sebagai berikut :

$$
\begin{aligned}
\mathrm{R} & =\frac{L}{M} \times 100 \% \\
\mathrm{R} & =\frac{40.832 .693,29}{44.872 .306,71} \times 100 \% \\
& =90,99 \%
\end{aligned}
$$

Hasil perhitungan menunjukkan bahwa nilai rentabilitas agroindustri tahu bulat pada perusahaan Asian sebesar 90,99 persen, ini berarti kemampuan perajin dalam menghasilkan laba selama satu kali proses produksi sebesar 90,99 persen dari modal (biaya) yang dikeluarkan.

\section{KESIMPULAN DAN SARAN \\ Kesimpulan}

Berdasarkan hasil penelitian dan pembahasan, maka dapat diambil kesimpulan sebagai berikut:

1. Biaya yang dikeluarkan oleh pengusaha agroindustri tahu bulat perusahaan Asian dalam satu kali proses produksi adalah Rp. 44.872.306,71. Penerimaan sebesar Rp.85.705.000,00 sehingga memperoleh pendapatan sebesar Rp. 40.832.693,29 dan nilai $\mathrm{R} / \mathrm{C}$ sebesar 1,90 .

2. Nilai tambah yang diperoleh pengusaha agroindustri tahu bulat perusahaan Asian yaitu Rp. 11.964,46 per kilogram.

3. Nilai rentabilitas usaha agroindustri tahu bulat perusahaan Asian adalah sebesar 90,99 persen.

\section{Saran}

Berdasarkan hasil pembahasan dan kesimpulan maka saran yang dapat disampaikan adalah :

1. Usaha agroindustri tahu bulat dapat memberikan keuntungan dan nilai tambah, sehingga pengusaha disarankan untuk mempertahankan dan meningkatkan kegiatan usahanya. Dengan lebih banyak lagi menarik para konsumen sehingga permintaan pun tinggi, dan dengan tingginya permintaan otomatis perusahaan dapat meningkatkan usahanya.

2. Untuk usaha agroindustri tahu bulat sebaiknya mempertahankan kualitas produk. Kualitas tahu bulat pada perusahaan Asian ini sudah bagus, mempunyai tekstur yang lembut, rasa yang khas enak dan gurih. Dengan adanya kualitas yang bagus dan tinggi usaha tersebut dapat menghadapi pesaing dari luar.

\section{DAFTAR PUSTAKA}

Adisarwanto, T. 2008. Budidaya Kedelai Tropika. Penebar Swadaya. Jakarta.

Arikunto, S., 2006. Prosedur Penelitian Suatu Pendekatan Praktik. Jakarta. Penerbit Rineka Cipta.

Nazir, M. 2009. Metode Penelitian. Ghalia Indonesia. Jakarta.

Rahim, A. Dan Hastuti. 2007. Ekonomika Pertanian (Pengantar, Teori, dan Kasus). Penebar Swadaya. Jakarta.

Riyanto, B. 2010. Dasar-Dasar Pembelanjaan Perusahaan. BPFE. Yogyakarta.

Rodjak, A. 2006. Manajemen Usahatani. Pustaka Giratuna Bandung Fakultas Pertanian Universitas Padjajaran. Bandung.

Suprapto, 2007. Proses Pengolahan dan Nilai Tambah Bakso Ikan Tenggiri. Universitas Mercu Buana. Jakarta.

Suratiyah, K. 2015. Ilmu Usahatani. Penebar Swadaya. Jakarta.

Suryana, A. 2005. Arah, Strategi dan Program Pembangunan Pertanian 2005-2009. Badan Penelitian dan Pengembangan Pertanian. Departemen Pertanian. Jakarta. 